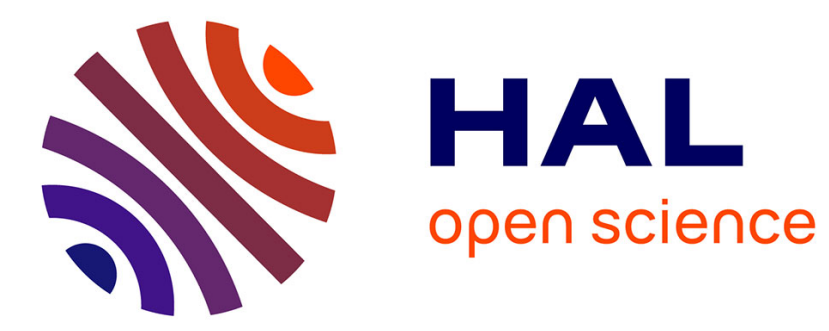

\title{
Observation of water vapor in the stratosphere of Jupiter with the Odin Space Telescope.
}

T. Cavalié, F. Billebaud, N. Biver, M. Dobrijevic, E. Lellouch, J. Brillet, J. Lecacheux, A. Hjalmarson, A. Sandqvist, U. Frisk, et al.

\section{- To cite this version:}

T. Cavalié, F. Billebaud, N. Biver, M. Dobrijevic, E. Lellouch, et al.. Observation of water vapor in the stratosphere of Jupiter with the Odin Space Telescope.. Planetary and Space Science, 2008, 56 (12), pp.1573-1584. 10.1016/j.pss.2008.04.013 . hal-00261908

\section{HAL Id: hal-00261908 \\ https://hal.science/hal-00261908}

Submitted on 10 Mar 2008

HAL is a multi-disciplinary open access archive for the deposit and dissemination of scientific research documents, whether they are published or not. The documents may come from teaching and research institutions in France or abroad, or from public or private research centers.
L'archive ouverte pluridisciplinaire HAL, est destinée au dépôt et à la diffusion de documents scientifiques de niveau recherche, publiés ou non, émanant des établissements d'enseignement et de recherche français ou étrangers, des laboratoires publics ou privés. 


\title{
Observation of water vapor in the stratosphere of Jupiter with the Odin Space Telescope
}

\author{
T. Cavalié ${ }^{a, *}$, F. Billebaud ${ }^{a}$, N. Biver ${ }^{b}$, M. Dobrijevic ${ }^{a}$, \\ E. Lellouch ${ }^{\mathrm{b}}$, J. Brillet ${ }^{\mathrm{a}}$, A. Lecacheux ${ }^{\mathrm{b}}, \AA$ A. Hjalmarson ${ }^{\mathrm{c}}$, \\ Aa. Sandqvist ${ }^{\mathrm{d}}$, U. Frisk ${ }^{\mathrm{e}}$, M. Olberg ${ }^{\mathrm{c}}$, The Odin Team, \\ E.A. Bergin ${ }^{f}$ \\ ${ }^{\mathrm{a}}$ Université Bordeaux 1; CNRS; OASU; LAB, UMR 5804, 331270 Floirac, France \\ ${ }^{\mathrm{b}}$ LESIA, Observatoire de Paris, 92195 Meudon, France \\ c Onsala Space Observatory, 43992 Onsala, Sweden \\ d Stockholm Observatory, 10691 Stockholm, Sweden \\ e Swedish Space Corporation, 17104 Solna, Sweden \\ ${ }^{\mathrm{f}}$ Harvard-Smithsonian Center for Astrophysics, Cambridge MA 02138, USA
}

\begin{abstract}
The water vapor line at $557 \mathrm{GHz}$ has been observed with the Odin space telescope with a high signal-to-noise ratio and a high spectral resolution on November 8, 2002. The analysis of this observation as well as a re-analysis of previously published observations obtained with the Submillimeter Wavelength Astronomy Satellite seem to favor a cometary origin (Shoemaker-Levy 9) for water in the stratosphere of Jupiter, in agreement with the ISO observation results. Our model predicts that the water line should become fainter and broader from 2007. The observation of such a temporal variablity would be contradictory with an IDP steady flux, thus
\end{abstract}


supporting the SL9 source hypothesis.

Key words: Jupiter, atmosphere, water, spectroscopy, Odin space telescope

$1 \quad 1$ Introduction

2 The Infrared Space Observatory has detected water vapor in the stratospheres 3 of the giant planets (Feuchtgruber et al. 1997; Feuchtgruber et al. 1999; Lel${ }_{4}$ louch 1999). The large amount of water measured above the condensation 5 level of vapor (cold trap at the tropopause) implies the presence of an ex6 ternal source of oxygenated compounds (Moses et al. 2000b; Lellouch et al. 7 2002). These compounds could be brought by interplanetary dust particles 8 (IDP), sputtering from the rings and/or satellites and large cometary im9 pacts. Observations of Jupiter carried out by ISO tend to prove that most of

the stratospheric water is due to the Shoemaker-Levy 9 (SL9) comet impacts in July 1994 (Lellouch et al. 2002), whereas Bergin et al. (2000) obtained satisfactory fits to the Submillimeter Wavelength Astronomy Satellite (SWAS) data by considering IDP infall, with a constant flux of $2.0 \times 10^{6} \mathrm{~cm}^{-2} \cdot \mathrm{s}^{-1}$.

The submillimeter satellite Odin was launched in 2001 and obtained a high resolution spectrum of Jupiter's water vapor line $\left(1_{10}-1_{01}\right)$ at $557 \mathrm{GHz}$ on November 8, 2002. This spectrum is presented in this work as well as a reanalysis of SWAS observations. Spectral analysis combined with the use of our photochemical model (Ollivier et al. 2000, adapted to Jupiter) provides new clues which help understanding the origin of water vapor in the stratosphere

* Tel: +33-5-5777-6123; fax: +33-5-5777-6110

Email address: Thibault.Cavalie@obs.u-bordeaux1.fr (T. Cavalié). 
A description of the observations is given in Sect. 2. Our photochemical and radiative transfer models are described in Sect. 3. Our results are presented in Sect. 4 and the different sources of $\mathrm{H}_{2} \mathrm{O}$ are discussed in Sect. 5 .

\section{Observations}

The space telescopes SWAS and Odin observed the water vapor $557 \mathrm{GHz}$ line on Jupiter in 1999, 2001 (SWAS) and 2002 (Odin). The resulting brightness temperature spectra have a signal-to-noise ratios of $\sim 17,10$ and 16 respectively for the 1999, 2001 and 2002 observations. The spectral resolution is about $1 \mathrm{~km} . \mathrm{s}^{-1}$ for the SWAS spectra and $0.6 \mathrm{~km} . \mathrm{s}^{-1}$ for the Odin spectrum.

The SWAS spectra are corrected for the Double Side Band (DSB) response of the instrument. Nevertheless, the SWAS spectra show broad features at $100 \mathrm{~km} \cdot \mathrm{s}^{-1}$ and more, which cannot be reproduced in models. These wings, probably due to instrumental effects as mentionned in Bergin et al. (2000) and Lellouch et al. (2002), cause an uncertainty on the continuum level of the emission. More details on the SWAS 1999 and 2001 observations can be found in Bergin et al. (2000) and Lellouch et al. (2002).

The Odin observations were carried out with the Acousto-Optical Spectrometer (AOS) in a classical position switching mode (Olberg et al. 2003). The receivers are operated in a Single Side Band (SSB) mode. The spectral band is 1 GHz. As Jupiter has a strong continuum emission at this frequency, stationary waves are generated within the instrument, causing ripples on the spectrum (Fig. 1). The subtraction of the ripples is the source of an uncertainty of $10 \%$ 


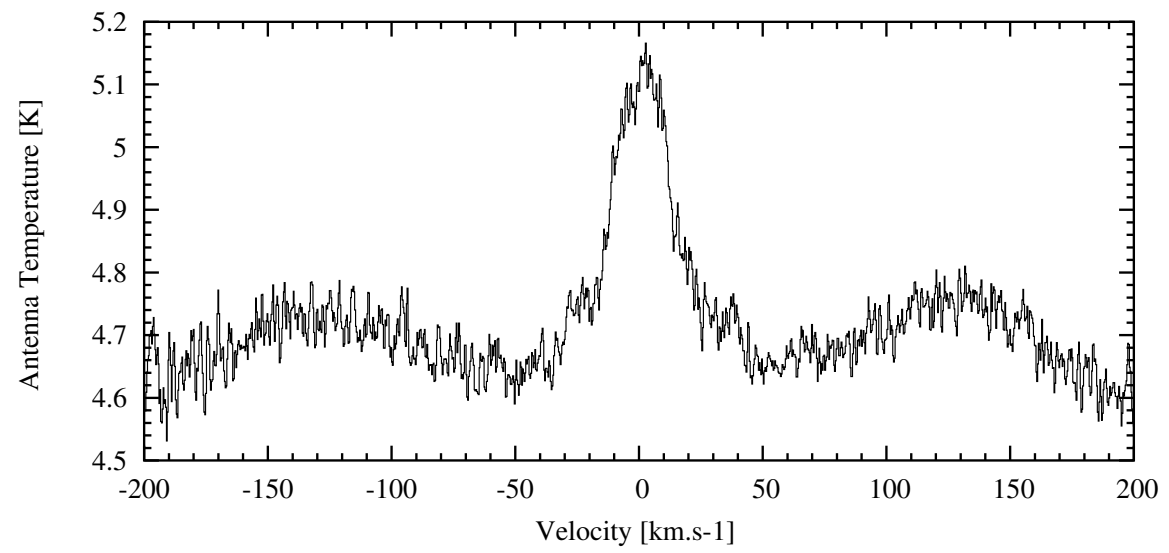

Fig. 1. Odin observations of Jupiter at the $\mathrm{H}_{2} \mathrm{O}\left(1_{10}-1_{01}\right)$ line frequency on November 8, 2002. The observed antenna temperature is displayed as a function of velocity. The signal-to-noise ratio is 16 .

43 on the line contrast and some uncertainty on the line wing shape.

${ }_{44}$ As the beam size $\left(3.3^{\prime} \times 4.5^{\prime}\right.$ for SWAS and $2.1^{\prime}$ for Odin $)$ is larger than the 45 planet size $(\sim 35-40 ")$, all the observed features correspond to the emission of 46 the whole planet. The line width is dominated by the smearing effect because 47 of limb equatorial velocity $\sim 12.6 \mathrm{~km} . \mathrm{s}^{-1}$ of the planet (Bergin et al. 2000). As

${ }_{51}\left(T_{B}=128.6 \mathrm{~K}\right)$.

\section{Modeling}

${ }_{53}$ We describe, in this section, details of our data analysis procedure that can 54 be summarized in the following way:

- A water vertical profile is simulated from a time-dependent 1D photochem- 
ical model. The main parameters that affect this profile are the altitude and the magnitude of water deposition (in the case of a sporadic cometary origin), the magnitude of the water influx (in case of a steady interplanetary dust particle flux) and the eddy diffusion coefficient in the stratosphere.

- A radiative-transfer model computes a synthetic spectrum for each water vapor profile.

- Comparison of observational data and synthetic spectra enables to constrain parameters of the photochemical model.

\subsection{Photochemical modeling}

We used a time-dependent photochemical model, derived from the model developed for Saturn by Ollivier et al. (2000) and which has been adapted to the case of the atmosphere of Jupiter. For each altitude and each chemical compound $i$, the code solves the continuity equation

${ }_{69} \quad \frac{\mathrm{d} n_{i}}{\mathrm{~d} t}=P_{i}-n_{i} L_{i}-\operatorname{div}\left(\phi_{i}\right)$

where $n$ is the concentration, $P$ the chemical production, $L$ the chemical loss and $\phi$ the vertical flux. This is a one-dimensional model since only the vertical transport is considered.

The model includes 46 oxygenated compounds and hydrocarbons and 593 reactions (photolysis processes and chemical reactions). Condensation near the tropopause is also considered. The eddy diffusion coefficient profile we took comes from Moses et al. (2005). We chose their nominal eddy profile called "model C"(see Sect. 5). The influx rates of oxygenated compounds (proportion of $\mathrm{H}_{2} \mathrm{O}, \mathrm{CO}_{2}$ and $\mathrm{CO}$ ) and $\mathrm{H}$ atoms were also taken from Moses 
Moses et al. (2000) showed that an IDP source is more likely than a ring/satellite source since there is a difference of $\sim 2$ orders of magnitude in the estimated fluxes. This is the reason why we chose to compare the results of two models: an IDP source model and a low-IDP+SL9 source model. For the sake of simplicity, the latter model will be called the SL9 model hereafter. The lack of spatial resolution of the observations allowed us to use disk-averaged mixing ratio vertical profiles for water, even if the SL9 impacts were all located in the southern hemisphere. The only input parameter we had to fix to test the IDP source hypothesis is the external flux of infalling water $\Phi_{\mathrm{H}_{2} \mathrm{O}}^{\mathrm{IDP}}$. In order to test the SL9 source hypothesis, we have built vertical profiles at the time of the impacts (July 1994) and let them evolve with the photochemical model until the time of the observations (September 1999, January 2001 for the SWAS data and November 2002 for the Odin data). The initial water vertical profiles have been built on the base of a low stationnary external flux and a sporadic input, due to the comet. The low stationnary input flux is modeled via an IDP model with a flux $\Phi_{\mathrm{H}_{2} \mathrm{O}}^{\mathrm{IDP}}=4 \times 10^{4} \mathrm{~cm}^{-2} \cdot \mathrm{s}^{-1}$ (Lellouch et al. 2002). This value is 2 orders of magnitude lower than a pure IDP model (see Sect. 4). The sporadic input of water due to the impacts was modeled via two parameters: the deposition pressure $p_{0}$ and the initial mixing ratio $q_{0}$ above the $p_{0}$ level (see Lellouch et al. 2002 for more details). For each computation, the value of $q_{0}$ was set to a constant value as a function of altitude (above the $p_{0}$ level).

Thus, we have two possibilities for the SL9 models. The first one consists of fixing the value of $p_{0}$ and adjusting the value of $q_{0}$ with the data. In the second case, we fix $q_{0}$ and adjust $p_{0}$. Some constraints exist on both $p_{0}$ and $q_{0}$. The most reliable constraint is probably the fact that the deposition level that was 


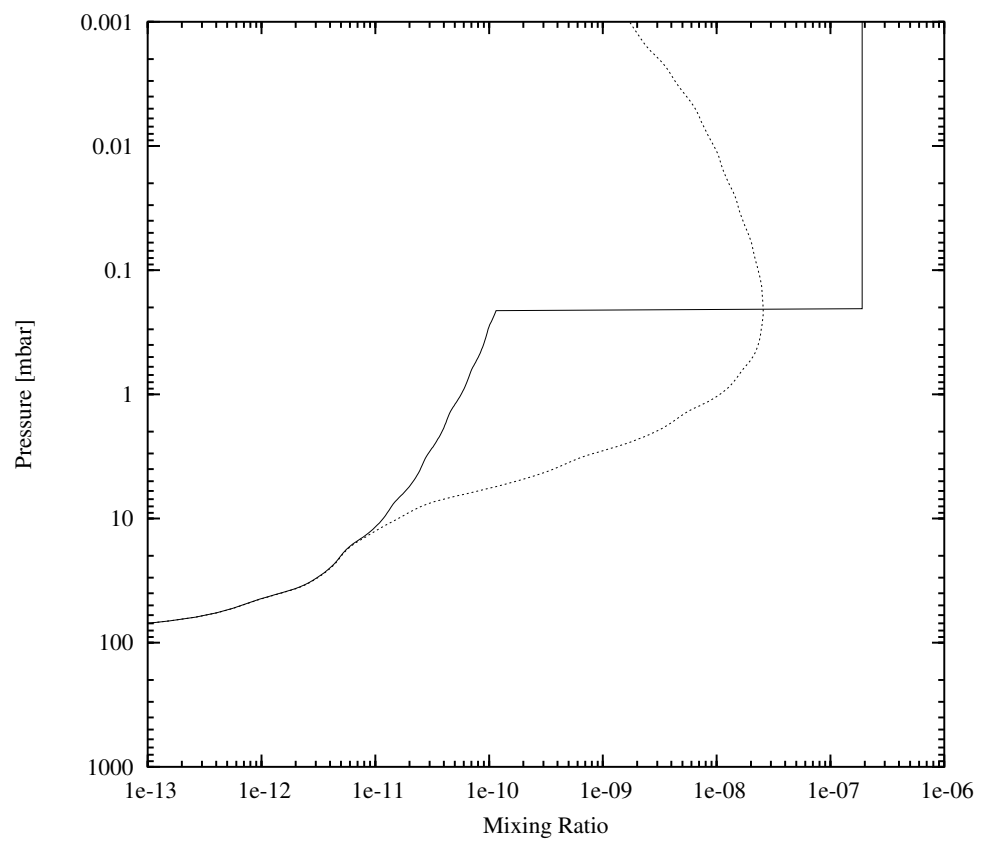

Fig. 2. Example of SL9 source vertical profiles of water at the time of the SL9 impacts $(07 / 1994)$ in solid line and at the time of the Odin observations (11/2002) in dashed lines. The evolution of water abundance is computed by the photochemical model. The water vapor mixing ratio is displayed as a function of atmospheric pressure. Profiles correspond to a fixed value of $p_{0}=0.2 \mathrm{mbar}$, and an adjusted value of $q_{0}=1.9 \times 10^{-7}$.

observed for CO during the SL9 impacts is $0.2 \pm 0.1$ mbar (Moreno 1998). From CO and CS post-impact observations, Lellouch et al. (1995), Lellouch et al. (1997) and Moreno et al. (2001) derived $p_{0}$ levels of 0.3 mbar, 0.04-0.2 mbar and 0.1 mbar (respectively). The other constraint lies on the observed column density of water vapor. Lellouch et al. (2002) inferred that the $\mathrm{H}_{2} \mathrm{O} / \mathrm{CO}$ ratio is equal to 0.07 in mass according to the entire ISO data set, thus fixing the $\mathrm{H}_{2} \mathrm{O}$ column density to $(2.0 \pm 0.5) \times 10^{15} \mathrm{~cm}^{-2}$. Such a value lead to the derival of a mixing ratio of water vapor of $6 \times 10^{-8}$ above the deposition level. An example of a SL9 model profile at the time of the impacts and at the time of the Odin observations is shown on Fig. 2. 
We modeled the observed submillimeter radiation with a line-by-line nonscattering radiative transfer model. We computed synthetic spectra of the $\mathrm{H}_{2} \mathrm{O} 557 \mathrm{GHz}$ line. The program represents the approximate spherical geometry of the planet so that planetary disk and limb contributions are taken into account. We assumed an uniform distribution of all other opacity sources and we adopted a mean thermal profile (see Fig. 3) of the atmosphere of Jupiter (Fouchet et al. 2000a) since our beam size is larger than the observed planetary disk. Continuum opacity is dominated by $\mathrm{H}_{2}-\mathrm{He}-\mathrm{CH}_{4}$ collision-induced absorption (Borysow et al. 1985, 1986 and 1988). Following Moreno (1998), the opacity due to the far wings of ammonia and phosphine lines was also included. We used the Fouchet et al. (2000b) ammonia and phosphine mixing ratio vertical profiles (see Fig. 4). Spectroscopic parameters for $\mathrm{NH}_{3}, \mathrm{PH}_{3}$ and $\mathrm{H}_{2} \mathrm{O}$ were taken from Pickett et al. (1998). The line widths are determined by the collisional line widths for $\mathrm{H}_{2}$ and He broadening. The broadening $\gamma$ and temperature dependance exponent $n$ values that we took for $\mathrm{NH}_{3}, \mathrm{PH}_{3}$ and $\mathrm{H}_{2} \mathrm{O}$ are summarized in Table 1 . All lines, except the $\mathrm{NH}_{3}$ ones, were assumed to be Voigt-shaped. Following Moreno (1998), we took a modified Van Vleck and Weisskopf line profile for ammonia.

The rapid rotation of Jupiter $(9.9 \mathrm{~h})$ induces the smearing of the disk-averaged line on the spectrum, because of the Doppler shifts due to the gas rotation velocity $\left(12.6 \mathrm{~km} . \mathrm{s}^{-1}\right.$ at the eastern and western limbs). The way this effect is taken into account is described in Bergin et al. (2000).

We briefly come back to the use of disk-averaged vertical profiles of mixing 


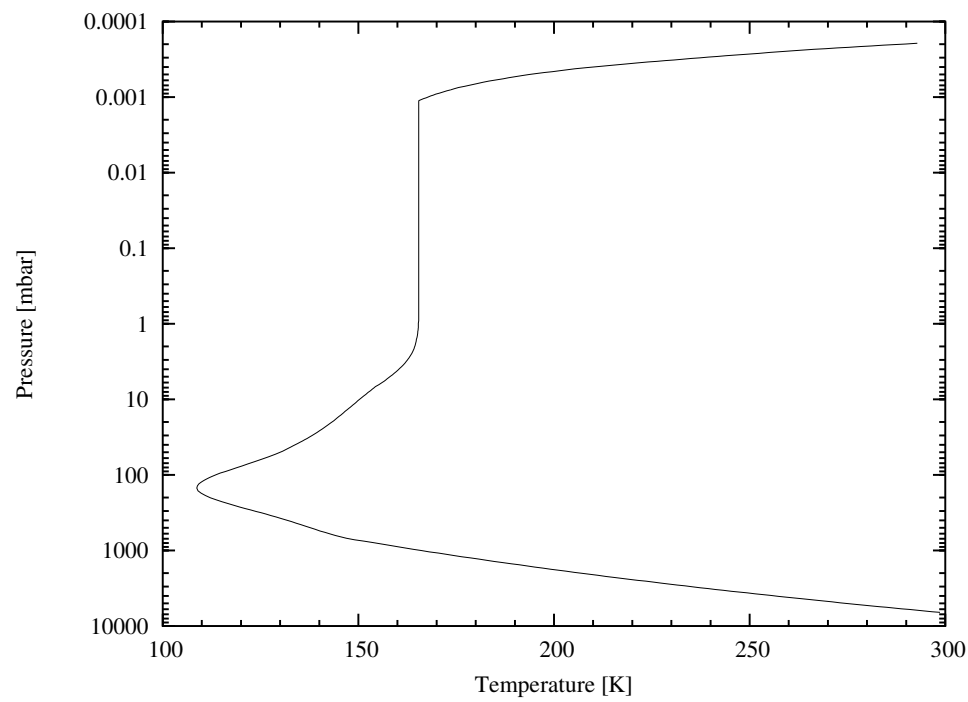

Fig. 3. Disk-averaged thermal profile of the atmosphere of Jupiter. The tropopause temperature is $109 \mathrm{~K}$. The profile is isothermal $(T=165.4 \mathrm{~K})$ between 1 mbar and $10^{-3}$ mbar. Reference: Fouchet et al. (2000a).

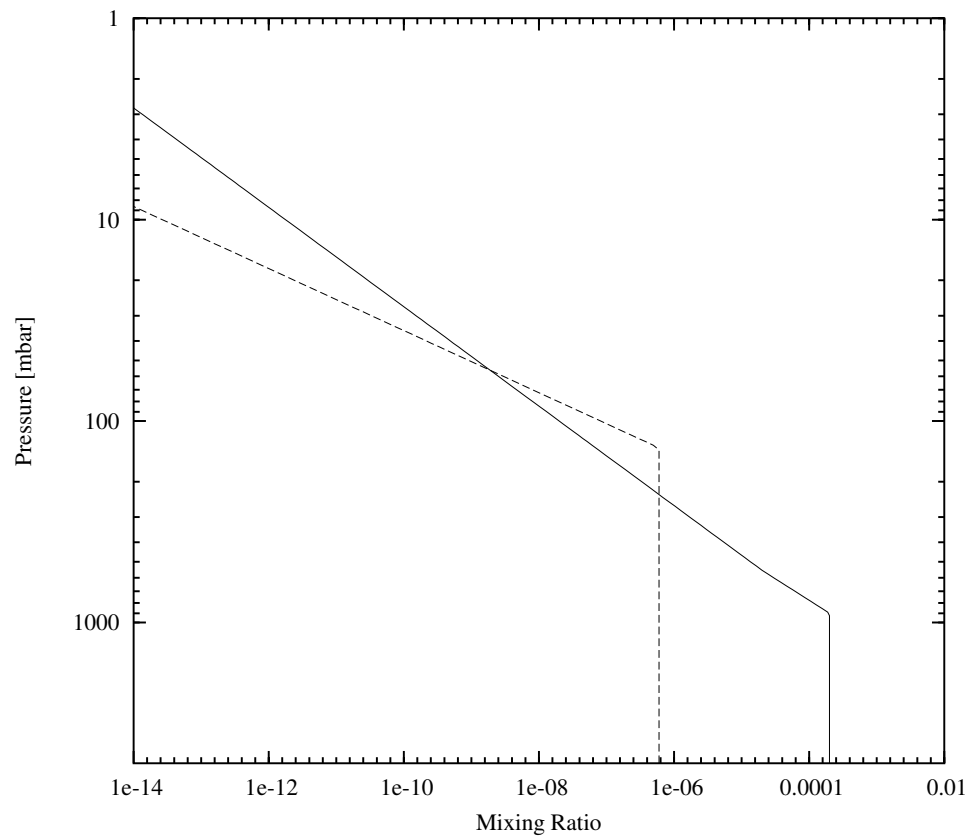

Fig. 4. Ammonia (solid line) and phosphine (long-dashed lines) mixing ratio vertical profiles as a function of pressure in Fouchet et al. (2000b).

ratio. The fact that the SL9 impacts were all located in the southern hemisphere is not a limitation to our hypothesis. All the impacts occured at the 


\begin{tabular}{cccc}
\hline$\gamma$ & $\mathrm{H}_{2}$ & $\mathrm{He}$ & Jupiter \\
\hline $\mathrm{NH}_{3}$ & 0.069 & & 0.069 \\
$\mathrm{PH}_{3}(2-1)$ & 0.1064 & 0.0606 & 0.1001 \\
$\mathrm{H}_{2} \mathrm{O}$ & 0.0811 & 0.0228 & 0.0731 \\
\hline$n$ & $\mathrm{H}_{2}$ & $\mathrm{He}$ & Jupiter \\
\hline $\mathrm{NH}_{3}$ & 0.67 & & 0.67 \\
$\mathrm{PH}_{3}$ & 0.73 & 0.30 & 0.67 \\
$\mathrm{H}_{2} \mathrm{O}$ & 0.9 & 0.50 & 0.85 \\
\hline
\end{tabular}

Table 1

Collisional line width $\gamma\left[\mathrm{cm}^{-1} . \mathrm{atm}^{-1}\right]$ (at $300 \mathrm{~K}$ ) and temperature dependance factor $n$ for $\mathrm{NH}_{3}, \mathrm{PH}_{3}$ and $\mathrm{H}_{2} \mathrm{O}$ with $\mathrm{H}_{2}$ and $\mathrm{He}$ and for Jupiter (a blank space means that no data are available). References: Berge \& Gulkis (1976) and Brown \& Peterson (1994) for $\mathrm{NH}_{3}$, Levy et al. (1993,1994) for $\mathrm{PH}_{3}$ and Dutta et al. (1993) for $\mathrm{H}_{2} \mathrm{O}$.

latitude of $44^{\circ} \mathrm{S}$. Longitudinal mixing proved to be efficient in the submillibar region. Indeed, $\mathrm{HCN}$ was observed at such pressure levels a few months after the comet impacts and the maps showed that it had already spread over several degrees in longitude (Bézard et al. 1997). So, the deposits quickly formed a longitudinal belt after the impacts. Thus we have to take into account the background amount of water present in the stratosphere of Jupiter, which is due to the low IDP flux $\left(\Phi_{\mathrm{H}_{2} \mathrm{O}}^{\mathrm{IDP}}=4 \times 10^{4} \mathrm{~cm}^{-2} \cdot \mathrm{s}^{-1}\right)$, and the SL9 input located at $44^{\circ} \mathrm{S}$, which is modeled via the parameters $p_{0}$ and $q_{0}$. By averaging those two kinds of vertical profiles over the surface of the planet, we obtain the kind of profile shown in Fig. 2 (see "hybrid model" in Lellouch et al. 2002), 
where $p_{0}$ is determined by the SL9 input and where $q_{0}$ is multiplied by the ratio between the surface of the SL9 longitudinal belt and the total surface of the planet. Using this approach, the values of $q_{0}$ we derive from the observations are disk-averaged values. A disk-averaged water vertical profile is adapted since the beam size is greater than the planet size.

\section{Results}

The best-fit models have been determined with a $\chi^{2}$ minimization process. All profiles and column density values are disk-averaged. One must note that an uncertainty of $5 \mathrm{~K}$ on the thermal profile would add an uncertainty of $0.4 \times 10^{15} \mathrm{~cm}^{-2}$ on the water vapor column density, $0.3 \times 10^{-7}$ on $q_{0}$ (in the case of a SL9 origin) and $0.6 \times 10^{6} \mathrm{~cm}^{-2} \cdot \mathrm{s}^{-1}$ (in the case of an IDP origin).

\subsection{SWAS data}

The observed Rayleigh-Jeans temperature continuum of the 1999 and 2001 observations are 126.4 K (Bergin et al. 2000) and 118.0 K (Lellouch et al. 2002) at $-60 \mathrm{~km} \cdot \mathrm{s}^{-1}$ respectively. After rescaling the continuum value to the brightness temperature continuum of our model, it appears that only the SL9 models give satisfactory fits to both sets of data, either in the wings or in terms of line

contrast. If we fit the line center, the IDP model with $\Phi_{\mathrm{H}_{2} \mathrm{O}}^{\mathrm{IDP}}=(3.4 \pm 0.5) \times 10^{6}$ $\mathrm{cm}^{-2} \cdot \mathrm{s}^{-1}$ results in spectra which have too broad wings (see Fig. 5). It is not possible fit within the 1- $\sigma$ error bars the line center and the wings at the same time. The best-fit model for both SWAS datasets is obtained with a SL9 model with $p_{0}=0.2$ mbar and $q_{0}=(1.8 \pm 0.5) \times 10^{-7}$ (see Figs. 5 and 6 ), leading to an 


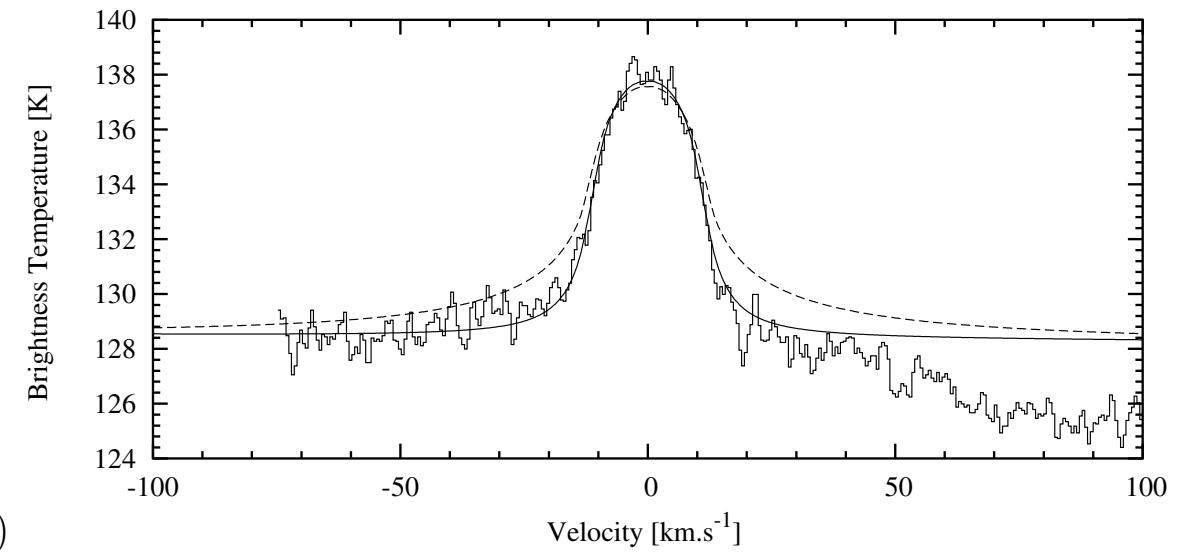

(a)

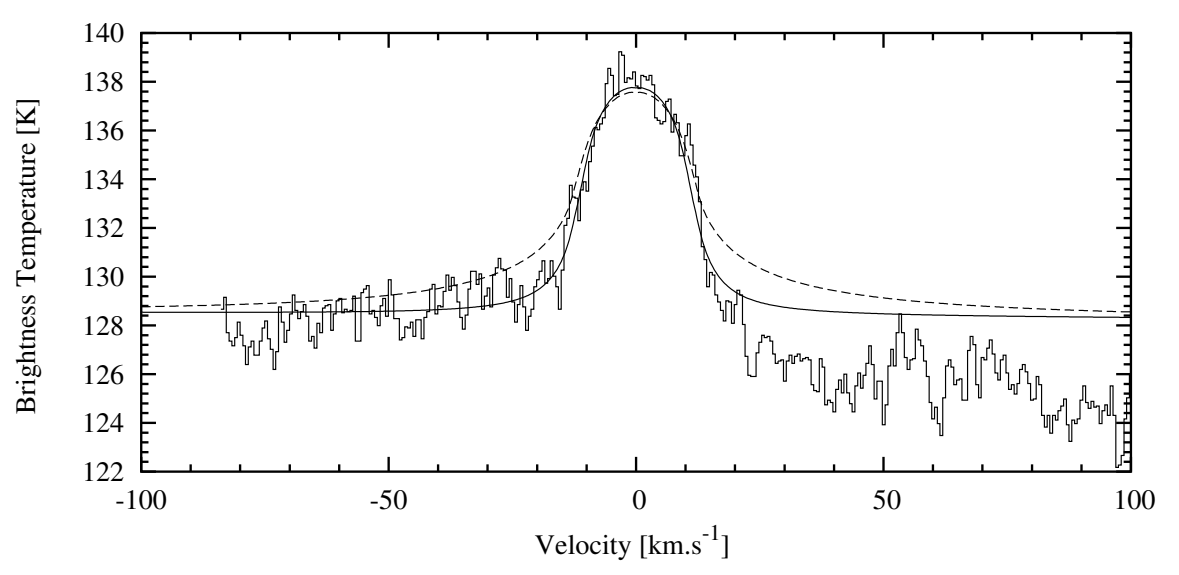

Fig. 5. Best-fit model to the (a) SWAS 1999 and (b) 2001 data obtained with a SL9 model with the initial parameters $p_{0}=0.2 \mathrm{mbar}$ and $q_{0}=1.8 \times 10^{-7}$ (solid lines). The IDP models (long-dashed lines) correspond to infall fluxes of $\Phi_{\mathrm{H}_{2} \mathrm{O}}^{\mathrm{IDP}}=3.4 \times 10^{6}$ $\mathrm{cm}^{-2} \cdot \mathrm{s}^{-1}$ for 1999 and 2001 respectively.

initial (in July 1994) column density of $(3.5 \pm 1.0) \times 10^{15} \mathrm{~cm}^{-2}$.

Nevertheless, the value of the continuum of both observations is quite uncertain, mostly due to the broad spectral features. Shifting downward the value of the continuum level within the error bar, it is possible to derive new values of the IDP flux that permits us to obtain synthetic spectra that match the SWAS data. For instance, if the continuumm of the 1999 and 2001 observations are set to $125.4 \mathrm{~K}$ and $117.0 \mathrm{~K}$ (respectively) instead of $126.4 \mathrm{~K}$ and 118 $\mathrm{K}$ (respectively) and then rescaled to the brightness temperature continuum 


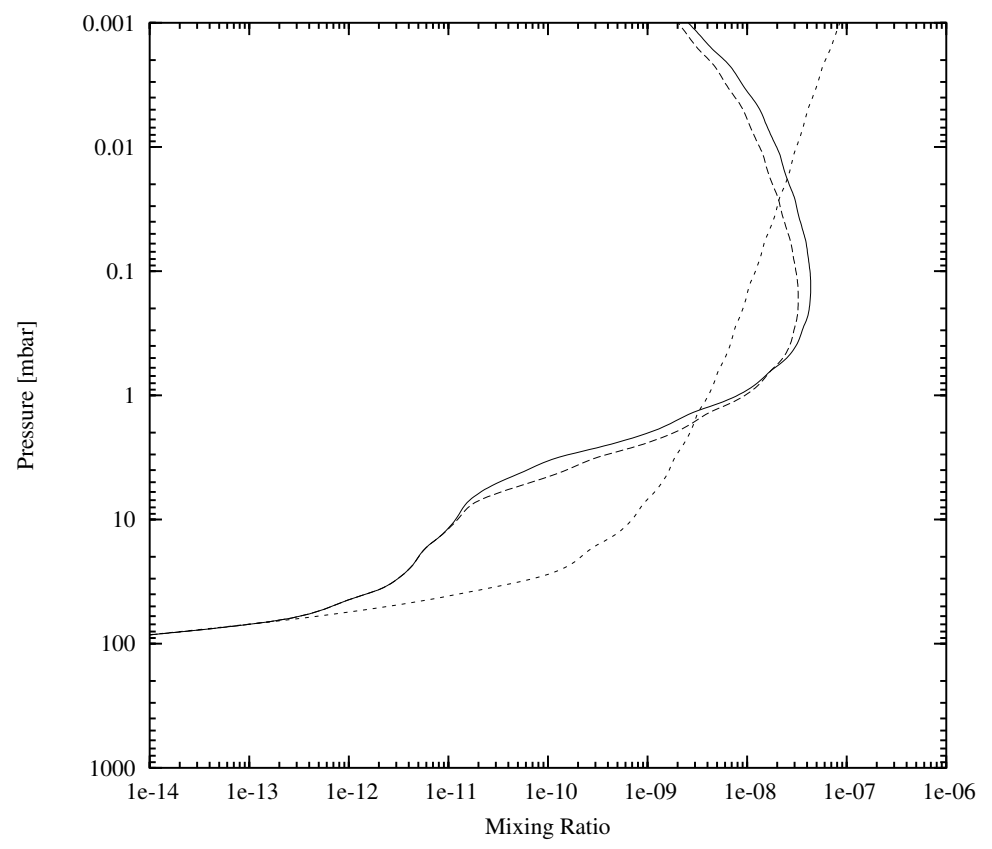

Fig. 6. Water mixing ratio vertical profiles as a function of pressure for a SL9 model with $p_{0}=0.2$ mbar and $q_{0}=1.8 \times 10^{-7}$ at the time of the SWAS 1999 observations (solid line) and at the time of the SWAS 2001 observations (long-dashed lines) and for IDP models with a steady flux of water $\Phi_{\mathrm{H}_{2} \mathrm{O}}^{\mathrm{IDP}}=3.4 \times 10^{6} \mathrm{~cm}^{-2} \cdot \mathrm{s}^{-1}$ (short-dashed line). The column density of water is $n_{\mathrm{H}_{2} \mathrm{O}}=3.5 \times 10^{15} \mathrm{~cm}^{-2}$ for the SL9 model at the time of the impacts and $n_{\mathrm{H}_{2} \mathrm{O}}=2.6 \times 10^{15} \mathrm{~cm}^{-2}$ for the IDP model.

of our model $\left(T_{B}=128.6 \mathrm{~K}\right)$, then the fits of IDP models are far better (Fig. $7)$. The flux we derive is $\Phi_{\mathrm{H}_{2} \mathrm{O}}^{\mathrm{IDP}}=(3.7 \pm 0.5) \times 10^{6} \mathrm{~cm}^{-2} \cdot \mathrm{s}^{-1}$ and the corresponding column density is $(2.8 \pm 0.4) \times 10^{15} \mathrm{~cm}^{-2}$. The synthetic spectrum is within the $1-\sigma$ error bars on the data over the $[-80:+20] \mathrm{km} \cdot \mathrm{s}^{-1}$ range. Finally, the IDP model cannot be ruled out at this stage, because of the uncertainty on the continuum level of each observation, even if a $\chi^{2}$ analysis shows that the SL9 model gives a better match to the data than the IDP model. All the IDP models that are considered for the SWAS data in what follows are models with downward shifted continuum (to $125.4 \mathrm{~K}$ and $117.0 \mathrm{~K}$, for 1999 and 2001 respectively). 
The SL9 model where $q_{0}$ is fixed to $6 \times 10^{-8}$ also gives a good fit for $p_{0}=(0.45 \pm$ 0.09) mbar (see Fig. 8). Here, the error bar on the $p_{0}$ value is not due to the $1-\sigma$ level of the spectrum. Indeed, the synthetic spectra with either $p_{0}=0.37$ mbar or $p_{0}=0.54$ mbar are outside the $1-\sigma$ level of the spectrum. This error bar is due to the fact that the integration step of the photochemical model is $5 \mathrm{~km}$. This results in 0.09 mbar steps in the $0.2-0.6$ mbar region. Taking $p_{0}=0.45$ mbar and $q_{0}=6 \times 10^{-8}$, the column density of water is $(2.6 \pm 0.6) \times 10^{15}$ $\mathrm{cm}^{-2}$ at the time of the impacts.

\subsection{Odin data}

After removing the ripple pattern, the line shows some asymmetry in the line wings. This, as well as the noise level, is a limitation in the determination of the best-fit model. Testing the IDP fluxes leads us to retrieve of a lower flux than the flux retrieved from the SWAS data. Indeed, the $\chi^{2}$ minimum is obtained for a flux value of $\Phi_{\mathrm{H}_{2} \mathrm{O}}^{\mathrm{IDP}}=(3.4 \pm 0.5) \times 10^{6} \mathrm{~cm}^{-2} \cdot \mathrm{s}^{-1}$ (see Fig. 9). This result is compatible with the SWAS initial results (before shifting downward the Rayleigh-Jeans temperature continuum). If we try to fit the line with an averaged best-fit model to the SWAS/Odin data $\left(\Phi_{\mathrm{H}_{2} \mathrm{O}}^{\mathrm{IDP}}=3.6 \times 10^{6} \mathrm{~cm}^{-2} \cdot \mathrm{s}^{-1}\right)$, then the line center is better reproduced (see Fig. 9). Nevertheless, such a modeling results in broader wings, but they still are within the 1- $\sigma$ error bars.

As for the SL9 model, restraining the bulk of water above an initial pressure level of 0.2 mbar, results in narrower lines than the IDP model. The line center as well as the wings are well reproduced with the synthetic spectra. When fixing $p_{0}$ to 0.2 mbar, the optimum water mixing ratio above this level is $q_{0}=2.0 \times 10^{-7}$. The uncertainty is $0.5 \times 10^{-7}$. When fixing $q_{0}$ to $6.0 \times 10^{-8}$ 


\section{Discussion}

The best-fit model parameters for each observation, as derived from $\chi^{2}$ minimization, are summarized in Table 2. From this set of parameters, we derived averaged values. For each model (IDP, SL9 with $q_{0}$ fixed and SL9 with $p_{0}$ fixed), the value obtained is affected a weight related to the signal-to-noise ratio of the observation. Doing this way, we obtained the averaged values used in Fig. 11.

First of all, when considering the SL9 source hypothesis and fixing the value of $q_{0}$ at $6 \times 10^{-8}$, we derive a deposition pressure level $p_{0}$ in the range of 0.45 0.54 mbar. The column density we derived is consistent with the value of Lellouch et al. (2002). However, even if our model does not provide a more precise value of $p_{0}$, the range of the values we derive is outside the ranges derived by Lellouch et al. (1997) and Moreno (1998) from CO observations at millimeter wavelengths at the time of the impacts, which are 0.04-0.2 mbar and $0.2 \pm 0.1$ mbar (respectively). Therefore, we regard this possibility as unlikely with regard to both SWAS and Odin data.

So, the models we have to compare are the IDP model and the SL9 model with $p_{0}=0.2$ mbar. We derived an external flux of water, originating from an IDP source, of $\Phi_{\mathrm{H}_{2} \mathrm{O}}^{\mathrm{IDP}}=(3.6 \pm 0.5) \times 10^{6} \mathrm{~cm}^{-2} \cdot \mathrm{s}^{-1}$. This value is greater than the one derived by Bergin et al. (2000) by a factor of less than 2. From their physical 
model, which only included vertical transport (no chemical or photochemical processes), the authors derived a deposition flux of $2.0 \times 10^{6} \mathrm{~cm}^{-2} \cdot \mathrm{s}^{-1}$. To obtain a narrower line from their model and thus to obtain their best-fit model, they increased the mixing ratio over pressure slope $(-\mathrm{d}(\log q) / \mathrm{d}(\log p))$ of their physical profile from 0.8 to 1.3 . Nevertheless, as noted by the authors, changing the slope could not simulate precisely the effects of photolysis, chemical reactions and the non-linearity of the interactions between these processes as well as vertical transport and condensation. Taking photolysis and chemical losses into account, they would probably have obtained a higher value for the flux consistent with our result.

With a SL9 model, we obtain $q_{0}=(1.9 \pm 0.5) \times 10^{-7}$ when fixing $p_{0}=0.2$ mbar. Lellouch et al. (2002) derived a column density of $(2.0 \pm 0.5) \times 10^{15} \mathrm{~cm}^{-2}$ at the time of the ISO observations. The column density we derived is $(3.7 \pm 1.0) \times 10^{15}$ $\mathrm{cm}^{-2}$ at the time of the impacts. This value is greater than the ISO value, but by taking photolysis, chemical reactions, vertical transport and condensation, this value decreases down to $(3.1 \pm 0.8) \times 10^{15} \mathrm{~cm}^{-2}$ at the time of ISO observations. This value is still above the Lellouch et al. (2002) value, but there is a small overlap on the ranges of values. Moreover, considering an uncertainty of $5 \mathrm{~K}$ on the thermal profile ends up in an additional uncertainty of $0.4 \times 10^{15} \mathrm{~cm}^{-2}$ on the column abundance. So, these values could well be consistent and an intermediate value of column density should be compatible with all inferred values. As the water vapor vertical profile of Lellouch et al. (2002) was computed from a vertical transport model, the ISO data should be re-analysed with a more complete photochemical model. This work still has to be done and its results could be directly comparable to ours.

The SL9 model quoted above better reproduces the line contrast as well as the 
SWAS 1999 and 2001

\begin{tabular}{|c|c|c|c|}
\hline Model & $\Phi_{\mathrm{H}_{2} \mathrm{O}}^{\mathrm{IDP}}\left[\mathrm{cm}^{-2} \cdot \mathrm{s}^{-1}\right]$ & $p_{0}[\mathrm{mbar}]$ & $q_{0}$ \\
\hline IDP & $(3.7 \pm 0.5) \times 10^{6}$ & - & - \\
SL9 $\left(q_{0}\right.$ fixed $)$ & $4.0 \times 10^{4}$ & $(0.45 \pm 0.09)$ & $6 \times 10^{-8}$ \\
SL9 $\left(p_{0}\right.$ fixed $)$ & $4.0 \times 10^{4}$ & 0.2 & $(1.8 \pm 0.5) \times 10^{-7}$ \\
\hline
\end{tabular}

Odin 2002

Table 2

\begin{tabular}{|c|c|c|c|}
\hline Model & $\Phi_{\mathrm{H}_{2} \mathrm{O}}^{\mathrm{IDP}}\left[\mathrm{cm}^{-2} \cdot \mathrm{s}^{-1}\right]$ & $p_{0}[\mathrm{mbar}]$ & $q_{0}$ \\
\hline IDP & $(3.4 \pm 0.5) \times 10^{6}$ & - & - \\
SL9 $\left(q_{0}\right.$ fixed $)$ & $4.0 \times 10^{4}$ & $(0.54 \pm 0.09)$ & $6 \times 10^{-8}$ \\
SL9 $\left(p_{0}\right.$ fixed $)$ & $4.0 \times 10^{4}$ & 0.2 & $(2.0 \pm 0.5) \times 10^{-7}$ \\
\hline
\end{tabular}

Best-fit model parameters for each set of data and each model, from which the averaged best-fit value are derived (see text).

line wings than the IDP model (see Fig. 11). A $\chi^{2}$ analysis clearly indicates that the SL9 model gives better fits to the data. However, all the IDP synthetic spectra are within the 1- $\sigma$ error bars on all observations. So, this model cannot be ruled out at this stage.

If the observed water would come from the SL9 comet, then the non-steady state created by the deposition of the cometary material above the $p_{0}$ level in our model should evolve towards a steady state where the only observable source of water would be the low IDP flux $\left(4 \times 10^{4} \mathrm{~cm}^{-2} \cdot \mathrm{s}^{-1}\right.$ in our model). From our computations, such a state is reached $\sim 400$ years after the im- 
pacts. As a result, the downward diffusion of water as well as the photochemical/chemical losses effects would first desaturate the line. Thus, the line contrast should first increase with time (see Fig. 12). Our photochemical model predicts that the line center temperature of the line should increase by $0.76 \mathrm{~K}$ from 1999 to 2007. Taking the noise level of the SWAS 1999 observations into account, our model predicts that this effect could only be observed in 2007 by reaching a signal-to-noise ratio of 50 with the Odin telescope. Afterwards, the amount of water decreasing more and more with time at submillibar pressures, the line should become fainter and broader and should tend towards the line that would be due to the low IDP flux only (see Fig. 12). This change should be observable with Herschel-HIFI.

One must not forget that the shape of the water vertical profile computed with a photochemical model highly depends on the vertical eddy diffusion coefficient profile $K(z)$. Due to strong uncertainties in the chemical scheme, each photochemical model derives, from comparison with observational data, a new value of $K(z)$ that can differ by about one order of magnitude at some altitudes (see Dobrijevic \& Parisot 1998, Dobrijevic et al. 2003 and Hébrard et al. 2007 for a detailed discussion on this point). For instance, as shown on Fig. 7 of Moses et al. (2005), many different $K(z)$ profiles have been inferred from past observations. At the submillibar pressure range, $K(z) \simeq 5 \times 10^{4}$ $\mathrm{cm}^{-2} \cdot \mathrm{s}^{-1}$ within a factor of 2 (Moreno et al. 2003). According to the Moses et al. (2005) model $\mathrm{C}$ value used in this work, $K(z)$ is equal to $7.8 \times 10^{4}$ $\mathrm{cm}^{-2} \cdot \mathrm{s}^{-1}$. At pressures between $0.1 \mathrm{mbar}$ and $100 \mathrm{mbar}$ (tropopause level), Gladstone et al. (1996) found values of $K(z)$ higher by a factor of $\sim 3$. So we have to consider the fact that another choice in the $K(z)$ profile could change our results. In the lower stratosphere, our adopted $K(z)$ profile gives 
a lower limit to $K(z)$ values (see Fig. 7 in Moses et al. 2005). By taking the Gladstone et al.(1996) $K(z)$ profile, we would obtain an eddy mixing in the lower stratosphere more efficient than in our study and it would result in more water above the condensation level. The direct impact on the spectra of such a change in the $K(z)$ profile would be a broadening of the wings. Thus, the IDP origin synthetic spectra would be out of the 1- $\sigma$ error bars of the SWAS and Odin observations. Finally, taking Moses et al. (2005) model C as a $K(z)$ profile is a conservative way of analysing the observed lines with regard to the implications noted above.

\section{Conclusion}

In this paper, we have shown that the high signal-to-noise ratio observations of water vapor in the stratosphere of Jupiter, carried out with SWAS and the Odin telescope between 1999 and 2002, favor a SL9 origin for water. Indeed, all observations are better fitted when the bulk of water is restricted to submillibar pressures. In our disk-averaged and simplified deposition model of the SL9 water, we derived a water mixing ratio of $1.9 \times 10^{-7}$ above an initial pressure deposition level of 0.2 mbar. In this model, a low IDP flux of $4 \times 10^{4}$ $\mathrm{cm}^{-2} \cdot \mathrm{s}^{-1}$ was also taken into account. This suggests a localised input of water, in terms of altitude, which is contradictory with a steady state resulting from an IDP permanent flux. Nevertheless, all synthetic spectra obtained from an IDP flux of $\Phi_{\mathrm{H}_{2} \mathrm{O}}^{\mathrm{IDP}}=(3.6 \pm 0.5) \times 10^{6} \mathrm{~cm}^{-2} \cdot \mathrm{s}^{-1}$ give fits that are within the $1-\sigma$ error bars of the observations, but the $\chi^{2}$ value is greater than the one computed from the SL9 model. In view of these results, the ISO data of 1997 should be re-analysed using the model developped in this work. 
Further observations, reaching a higher signal-to-noise ratio are needed to state on the origin of water vapor in the stratosphere of Jupiter, even if the SL9 origin is favored by both SWAS and Odin observations. The analysis of the latest Odin observations (August 2007) is underway. Moreover, Herschel observations with the HIFI instrument $(500 \mathrm{GHz}-2000 \mathrm{GHz})$ should allow obtaining a signal-to-noise ratio with a comparable spectral resolution in reasonable times. Such a high signal-to-noise ratio would enable us to better resolve the line wing shape in order to discriminate between both origins. Moreover, a temporal variability of the line could be brought to light. Such a variability should not be expected with an IDP origin. Indeed, Moses et al. (2000a) suggested that the production of the IDP is dominated by short-period comets. Selsis et al. (2004) showed that 48 short-period ( $~ 5-10$ year periods) comets approach Jupiter's orbit at less than the Roche lobe radius of the planet. So, the IDP flux on Jupiter should be steady. Finally, using HIFI at the highest frequencies would result in a sufficient spatial resolution to carry out maps of Jupiter at water vapor frequencies. A latitudinal inhomogeneous distribution of water, with an increase of its amount in the southern hemisphere would be a strong signature of a SL9 impact origin and could provide information on the horizontal diffusion at the submillibar level.

\section{References}

[1] Berge, G. L., Gulkis, S., 1976, In "Jupiter, studies of the interior, atmosphere, magnetosphere and satellites", ed. T. Gehrels, 621-692

[2] Bergin, E. A., Lellouch, E., Harwit, M., Gurwell, M. A., Melnick, G. J., Ashby, M. L. N., Chin, G., Erickson, N. R., Goldsmith, P. F., Howe, J. E., Kleiner, S. C., Koch, D. G., Neufeld, D. A., Patten, B. M., Plume, R., 
Schneider, R., Snell, R. L., Stauffer, J. R., Tolls, V., Wang, Z., Winnewisser,

G., Zhang, Y. F., 2000, The Astrophysical Journal, 539, L147-L150

[3] Bézard, B., Griffith, C. A., Kelly, D. M., Lacy, J. H., Greathouse, T., Orton, G., 1997, Icarus, 125, 94-120

[4] Borysow, J., Trafton, L., Frommhold, L., Birnbaum, G., 1985, The Astrophysical Journal, 296, 644-654

[5] Borysow, A., Frommhold, L., 1986, The Astrophysical Journal, 304, 849865

[6] Borysow, J., Frommhold, L., Birnbaum, G., 1988, The Astrophysical Journal, 326, 509-515

[32] Brown, L. R., Peterson, D. B., 1994, Journal of Molecular Spectroscopy, $168,593-606$

[8] Dobrijevic, M., Parisot, J.-P., 1998, Planetary and Space Science, 46, 491505

[9] Dobrijevic, M., Ollivier, J.-L., Billebaud, F., Parisot, J.-P., 2003, Astronomy and Astrophysics, 398, 335-344

[10] Dutta, J. M., Jones, C. R., Goyette, T. M., De Lucia, F. C., 1993 Icarus, $102,232-239$

[11] Feuchtgruber, H., Lellouch, E., de Graauw, T., Bézard, B., Encrenaz, T., Griffin, M., 1997, Nature, 389, 159-162

[12] Feuchtgruber, H., Lellouch, E., Encrenaz, T., Bézard, B., Coustenis, A., Drossart, P., Salama, A., de Graauw, T., Davis, G. R., 1999, The Universe as Seen by ISO, Eds., P. Cox \& M.F. Kessler, ESA-SP, 427, 133

[13] Fouchet, T., Lellouch, E., Bézard, B., Feuchtgruber, H., Drossart, P., Encrenaz, T., 2000a, Astronomy and Astrophysics, 355, L13-L17

[14] Fouchet, T., Lellouch, E., Bézard, B., Encrenaz, T., Drossart, P., Feucht- 
gruber, H., de Graauw, T., 2000b, Icarus, 143, 223-243

[15] Gladstone, G.R., Allen, M., Yung, Y. L., 1996, Icarus, 119, 1-52

[16] Hébrard, E., Dobrijevic, M., Bénilan, Y., Raulin, F., 2007, Planetary and Space Science, 55, 1470-1489

[17] Lellouch, E., Paubert, G., Moreno, R., Festou, M. C., Bézard, B., Bockelée-Morvan, D., Colom, P., Crovisier, J., Encrenaz, T., Gautier, D., Marten, A., Despois, D., Strobel, D. F., Sievers, A., 1995, Nature, 373, $592-595$

[18] Lellouch, E., Bézard, B., Moreno, R., Bockelée-Morvan, D., Colom, P., Crovisier, J., Festou, M., Gautier, D., Marten, A., Paubert, G., 1997, Planetary and Space Science, 45, 1203-1212

[19] Lellouch, E., 1999, The Universe as Seen by ISO, Eds., P. Cox \& M. F. Kessler, ESA-SP, 427, 125

[20] Lellouch, E., Bézard, B., Moses, J. I., Davis, G. R., Drossart, P., Feuchtgruber, H., Bergin, E. A., Moreno, R., Encrenaz, T., 2002, Icarus, 159, $112-131$

[21] Levy, A, Lacome, N., Tarrago, G., 1993, Journal of Molecular Spectroscopy, 157, 172-181

[22] Levy, A, Lacome, N., Tarrago, G., 1994, Journal of Molecular Spectroscopy, 166, 20-31

[23] Moreno, R., 1998, PhD Thesis, Université Paris VI

[24] Moreno, R., Marten, A., Biraud, Y., Bézard, B., Lellouch, E., Paubert, G., Wild, W., 2001, Planetary and Space Science, 49, 473-486

[25] Moreno, R., Marten, A., Matthews, H. E., Biraud, Y., 2003, Planetary and Space Science, 51, 591-611

[26] Moses, J. I., Bézard, B., Lellouch, E., Gladstone, G. R., Feuchtgruber, 
H., Allen, M., 2000a, Icarus, 143, 244-298

[27] Moses, J. I., Lellouch, E., Bézard, B., Gladstone, G. R., Feuchtgruber, H., Allen, M., 2000b, Icarus, 145, 166-202

[28] Moses, J. I., Fouchet, T., Bézard, B., Gladstone, G. R., Lellouch, E., Feuchtgruber, H., 2005, Journal of Geophysical Research, 110, E08001

[29] Olberg, M., Frisk, U., Lecacheux, A., Olofsson, A. O., Baron, P., Bergman, P., Florin, G., Hjalmarson, Å, Larsson, B., Murtagh, D., Olofsson, G., Pagani, L., Sandqvist, Aa., Teyssier, D., Torchinsky, S. A., Volk, K., 2003, Astronomy and Astrophysics, 402, L35-L38

[30] Ollivier, J.-L., Dobrijevic, M., \& Parisot, J.-P., 2000, Planetary and Space Science, 48, 699

[31] Pickett, H. M., Poynter, R. L., Cohen, E. A., Delitsky, M. L., Pearson, J. C., Muller, H. S. P., 1998, Journal of Quantitative Spectroscopy and Radiative Transfer, 60, 883

[32] Selsis, F., Brillet, J., Rapaport, M., 2004, Astronomy and Astrophysics, $416,783-789$ 

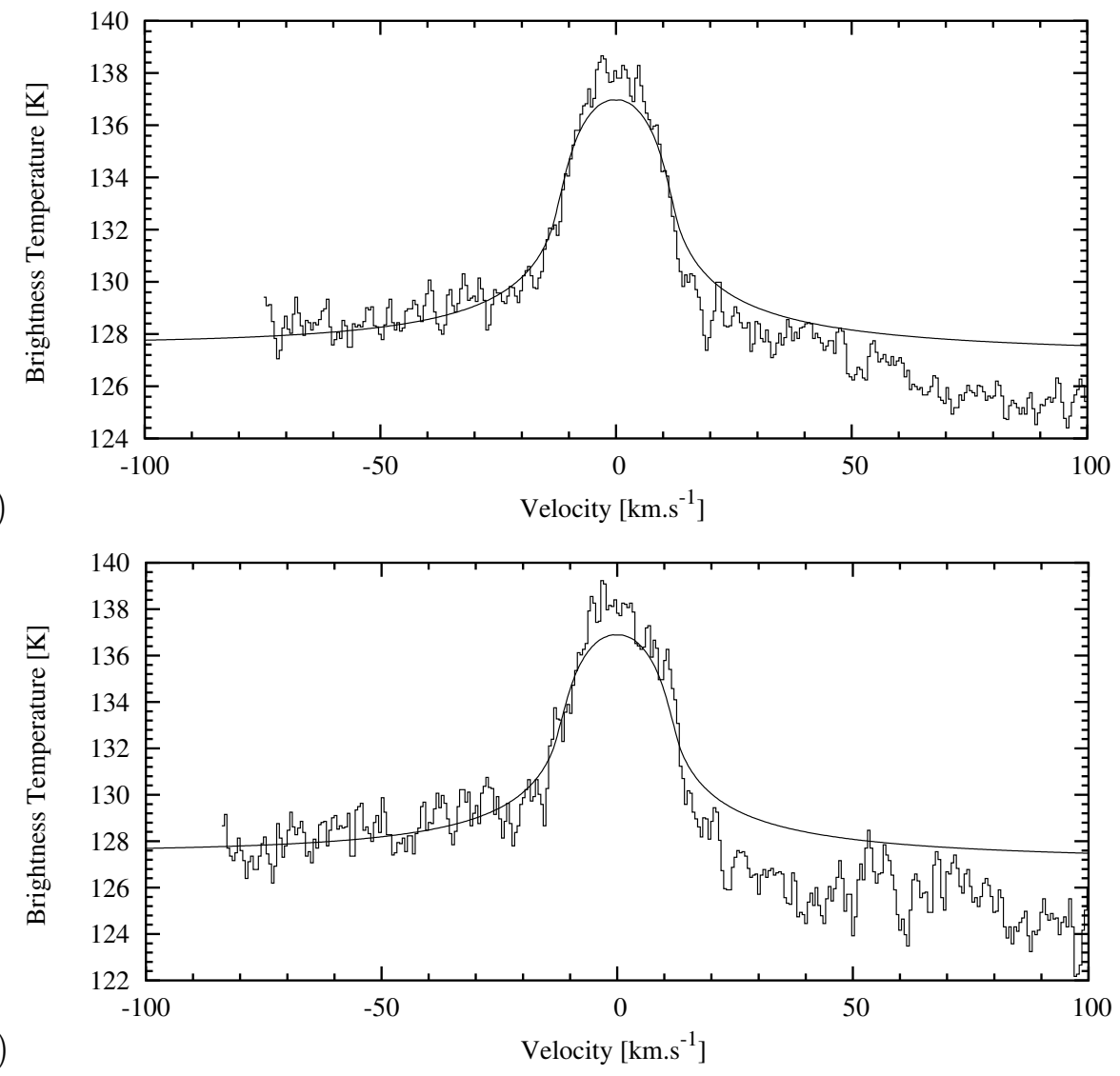

(b)

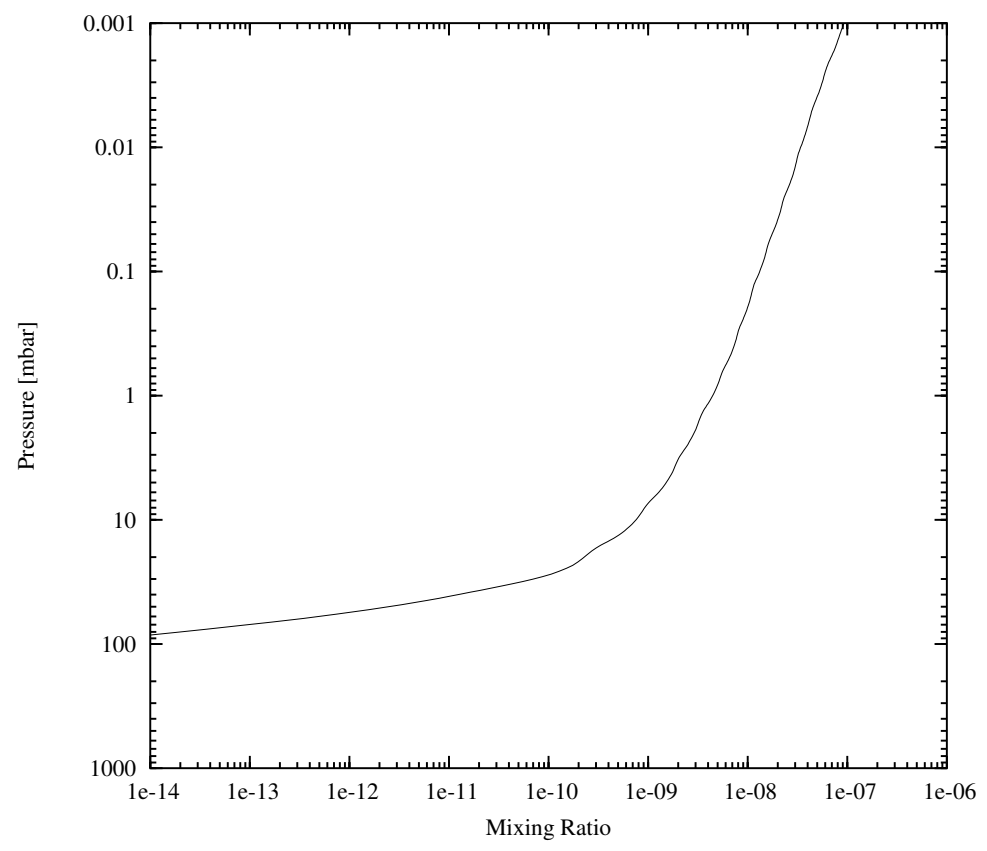

Fig. 7. Brightness temperature spectra as observed by SWAS (a) in 1999 and (b) in 2001. Both spectrum continuum have been rescaled so as to obtain a better fit of the line wings with an IDP model. (c): water mixing ratio vertical profile as a function of pressure resulting from the observed flux of $\Phi_{\mathrm{H}_{2} \mathrm{O}}^{\mathrm{IDP}}=3.7 \times 10^{6} \mathrm{~cm}^{-2} \cdot \mathrm{s}^{-1}$. 

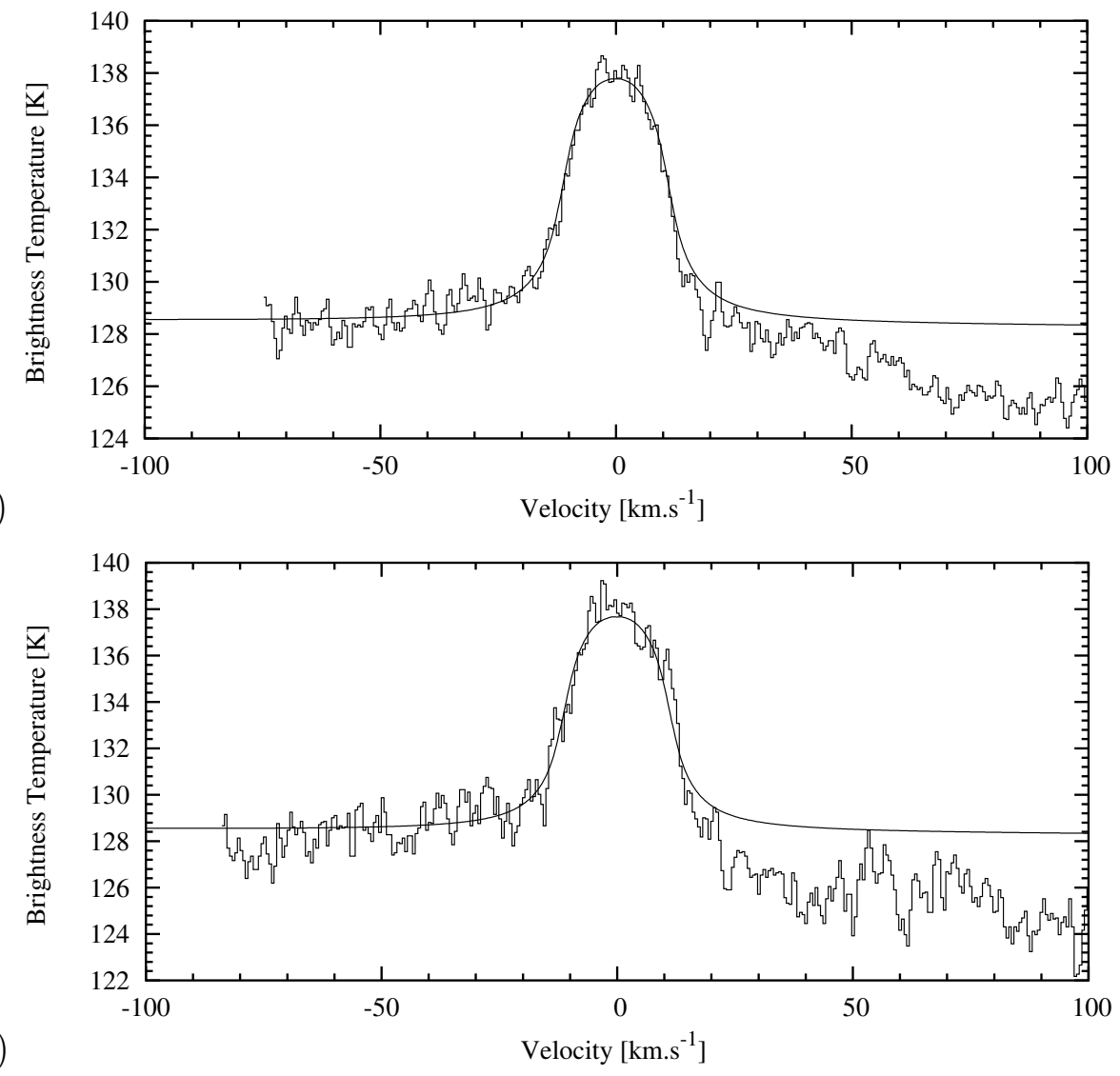

(b)

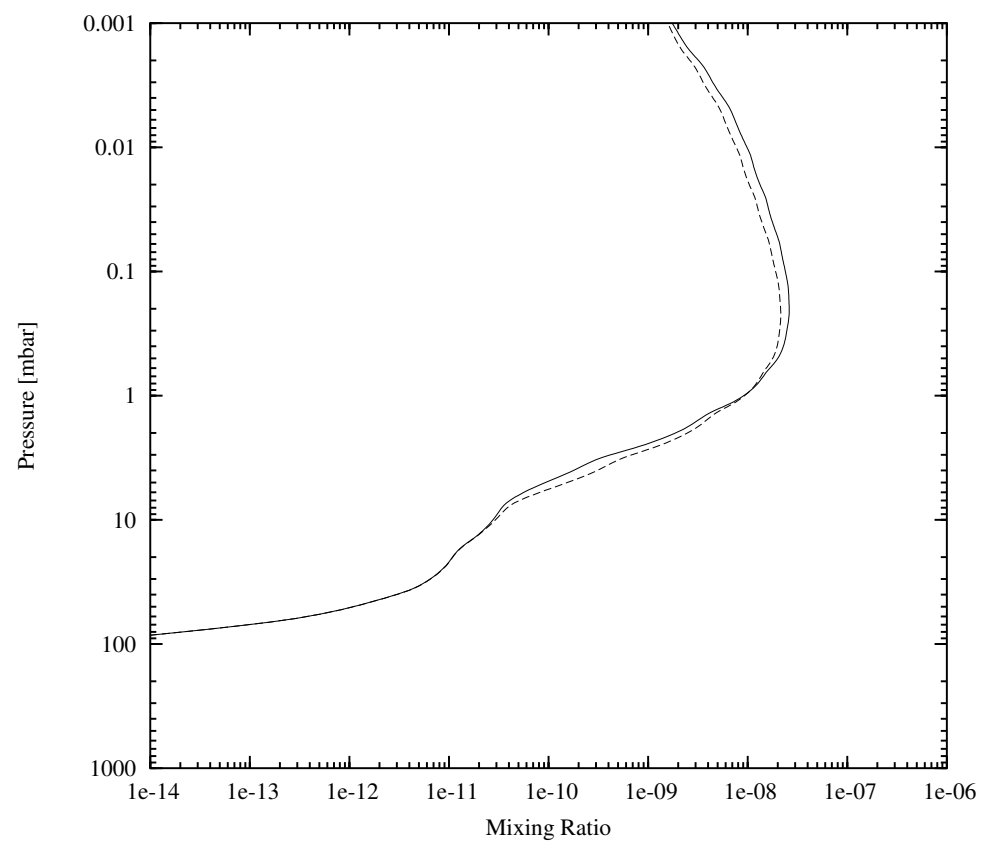

Fig. 8. SL9 model results compared to the (a) SWAS 1999 and (b) SWAS 2001 observed spectra, when fixing $q_{0}=6.0 \times 10^{-8}$. The derived initial deposition pressure level $p_{0}$ is 0.45 mbar. (c): corresponding water mixing ratio vertical profiles at the time of the observations (solid line for 1999 and long-dashed lines for 2001). 


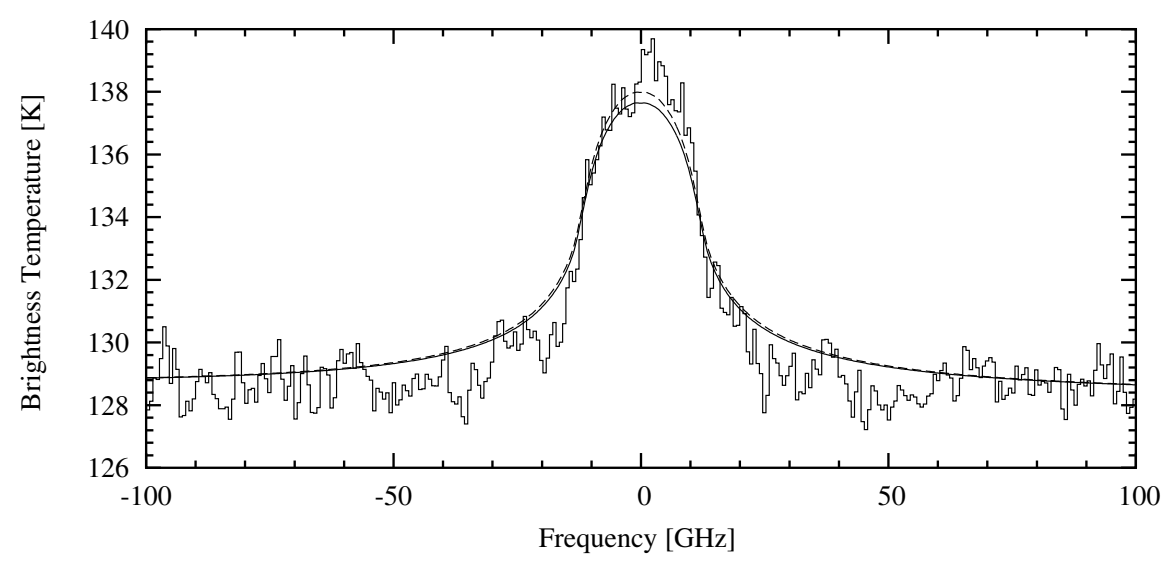

Fig. 9. Odin 2002 data modeled with IDP models. The solid line corresponds to a flux of $\Phi_{\mathrm{H}_{2} \mathrm{O}}^{\mathrm{IDP}}=3.4 \times 10^{6} \mathrm{~cm}^{-2} \cdot \mathrm{s}^{-1}\left(\chi^{2}\right.$ minimum value $)$. The long-dashed lines correspond to the overall (SWAS and Odin data) best-fit model $\left(\Phi_{\mathrm{H}_{2} \mathrm{O}}^{\mathrm{IDP}}=3.6 \times 10^{6} \mathrm{~cm}^{-2} \cdot \mathrm{s}^{-1}\right)$.

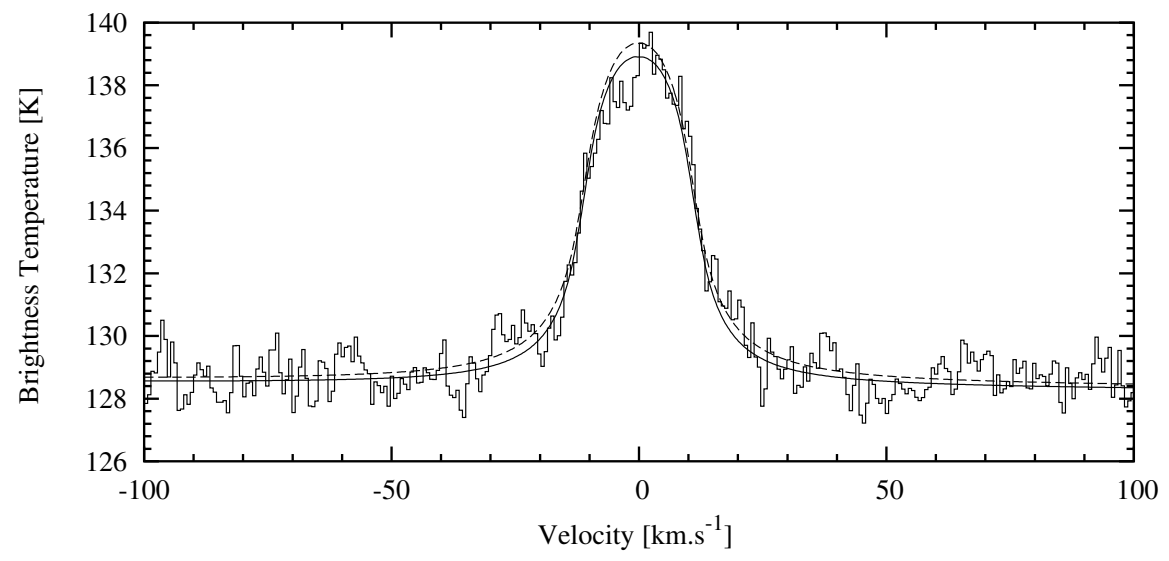

Fig. 10. Odin 2002 data modeled with SL9 models. When $p_{0}$ is fixed to 0.2 mbar, the derived $q_{0}$ value is $2.0 \times 10^{-7}$ (solid line) whereas when fixing $q_{0}$ to $6.0 \times 10^{-8}$, the derived $p_{0}$ pressure level is 0.54 mbar (long-dashed lines). 

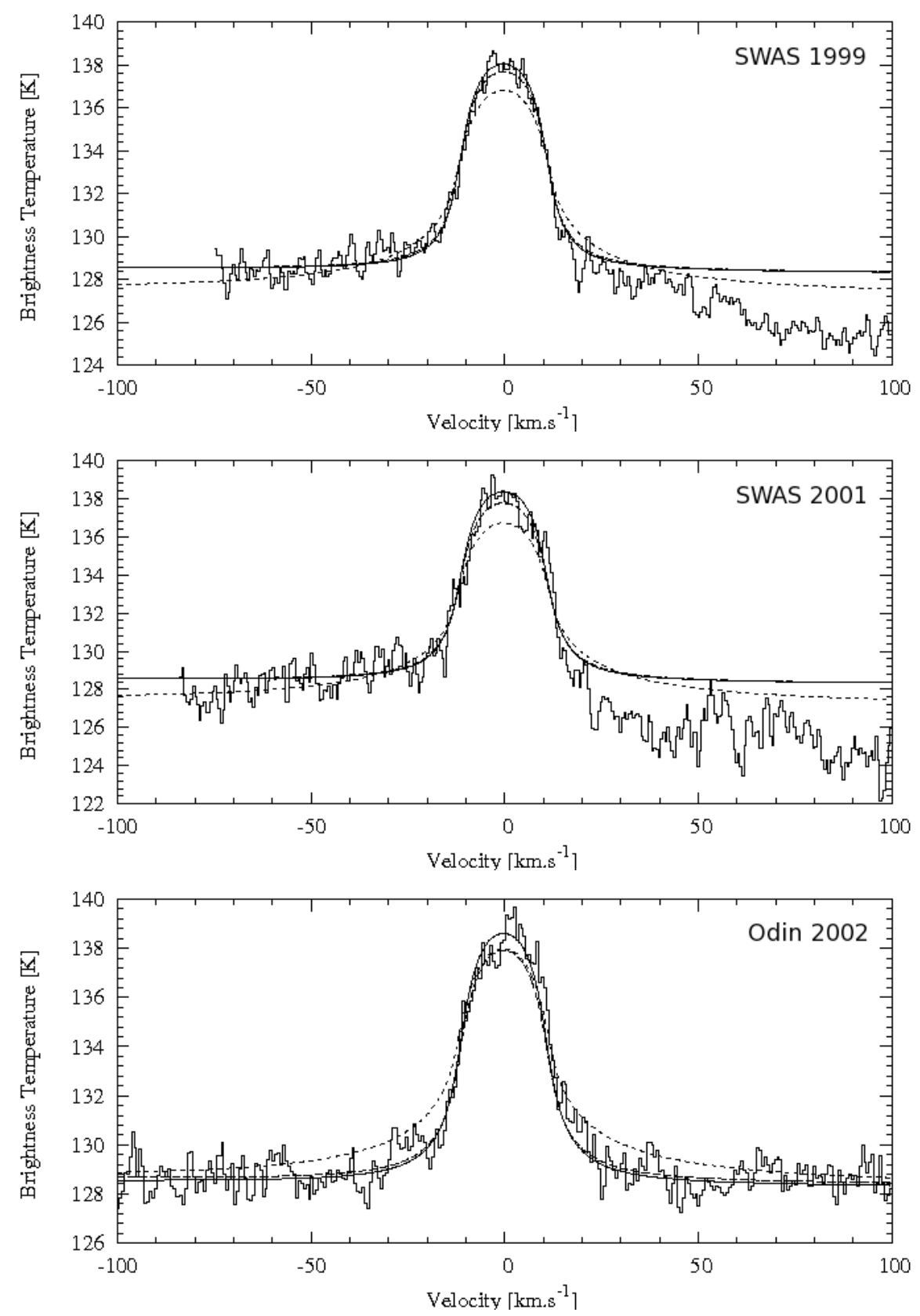

Fig. 11. Overall best-fit models for the SWAS 1999 and 2001 and Odin 2002 observations. Solid lines: SL9 model with $p_{0}=0.2 \mathrm{mbar}$ (fixed) and $q_{0}=1.9 \times 10^{-7}$; longdashed lines: SL9 model with $p_{0}=0.45$ mbar and $q_{0}=6 \times 10^{-8}$ (fixed); short-dashed lines: IDP model with a steady infall flux of water $\Phi_{\mathrm{H}_{2} \mathrm{O}}^{\mathrm{IDP}}=3.6 \times 10^{6} \mathrm{~cm}^{-2} \cdot \mathrm{s}^{-1}$. The overall best-fit parameter have been obtained from Table 2 and by taking the signal-to-noise ratio of each observation into account. Doing this way, the SWAS 1999 observations have a lower impact on the results than the SWAS 2001 and Odin 2002 observations. 


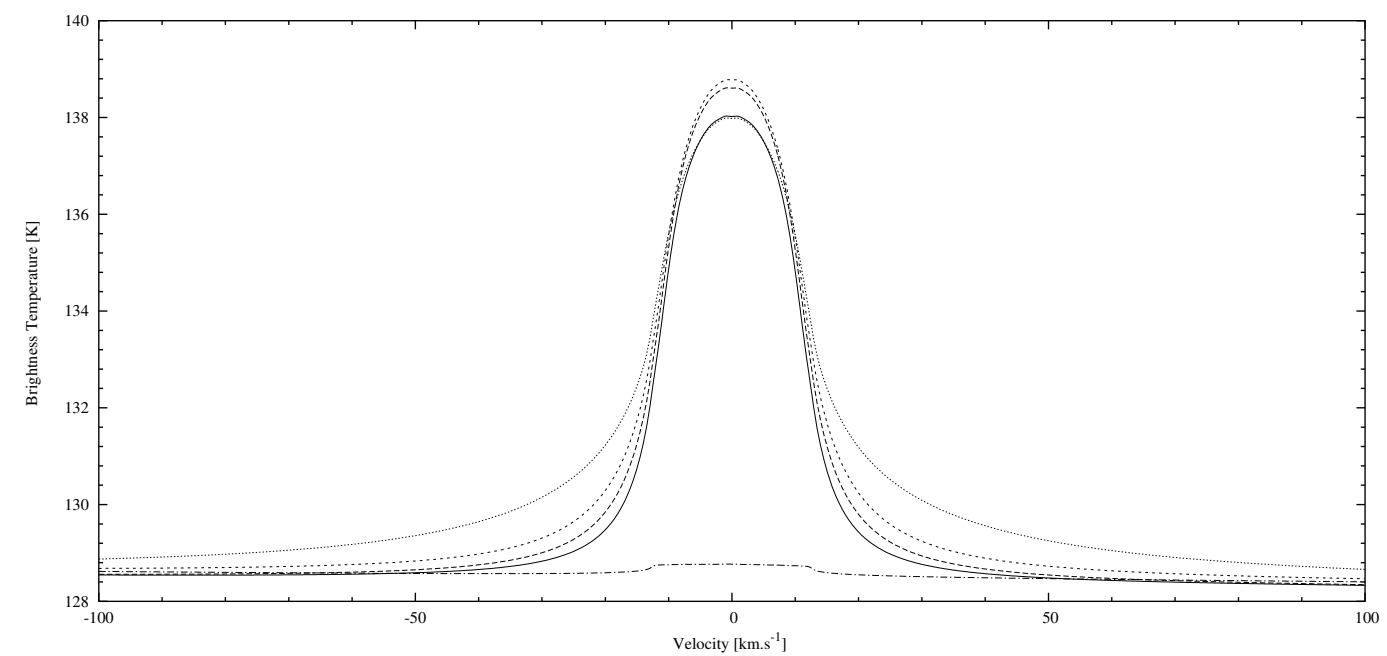

Fig. 12. Evolution of the line shape with time, in the case of a SL9 origin. Vertical distribution of water has been computed with our photochemical model at various dates. Parameters $p_{0}$ and $q_{0}$ have been set to 0.2 mbar and $1.9 \times 10^{-7}$ respectively. The spectrum is plotted at the time of SWAS 1999 observations (solid line), Odin 2002 observations (long-dashed lines), in 2007 as observed with the Odin telescope (short-dashed lines). Once all the water deposited by SL9 will be removed by photochemistry, transport and condensation, the remaining water will only be due to the low IDP flux $\left(\Phi_{\mathrm{H}_{2} \mathrm{O}}^{\mathrm{IDP}}=4 \times 10^{4} \mathrm{~cm}^{-2} \cdot \mathrm{s}^{-1}\right)$. The dashed-dotted lines represent the line due to this flux, as it would be observed by Odin. The line resulting from an IDP model $\left(\Phi_{\mathrm{H}_{2} \mathrm{O}}^{\mathrm{IDP}}=3.6 \times 10^{6} \mathrm{~cm}^{-2} \cdot \mathrm{s}^{-1}\right)$ is plotted for comparison in dotted lines. 